\title{
Investigation on Manufacturing Process in Some Elamite Copper Alloy Artefacts from Haft Tappeh, South-west Iran
}

\author{
Omid Oudbashi ${ }^{1}$, and Parviz Davami ${ }^{2}$ \\ ${ }^{1}$ Faculty of Conservation, Art University of Isfahan, Isfahan, Iran. \\ 2. Faculty of Material Science and Engineering, Sharif University of Technology, Tehran, Iran.
}

The archaeometallurgy of copper have been pioneer technologies in ancient Iran and goes back to about ten thousand years ago in Iranian Plateau $[1,2]$. The Haft Tappeh Middle Elamite Site is located in Southwest Iran and have been an important city belonging to early phase of Middle Elamite period (14th century BCE) [3, 4]. Based on various metallurgical evidences found in archaeological excavations, such as metalworking workshop, slag, smelted copper as well as numerous copper alloy artefacts, extensive metallurgical activities have done in Haft Tappeh and it has been an important center in smelting and manufacturing copper alloys in second millennium BC [4, 5]. To identify metallurgical process of metallic artefacts in Haft Tappeh including alloying composition, inclusions and phases as well as manufacturing and shaping, seven metallic fragments have studied by Scanning Electron Microscopy with Energy Dispersive X-ray Spectrometry (SEM-EDS) and optical microscopy.

The chemical analysis by SEM-EDS proves that the samples aren't similar in composition: four samples have made by tin bronze (tin: 2.61-7.06 wt.\%), two samples have made by arsenic copper (arsenic: 1.59$2.75 \mathrm{wt.} \%$ ) and one is copper (Table 1). Lead has been detected in one bronze sample (2.24 wt.\%), but has measured as trace element in others. Other elements such as $\mathrm{S}, \mathrm{Ni}, \mathrm{Fe}, \mathrm{Ca}$ and $\mathrm{O}$ have detected as trace in some samples. The analytical results by SEM-EDS shows that the samples have made by different copper alloys: tin bronze, leaded tin bronze, arsenic copper and copper [6]. These are very similar analysis results from some other copper alloys belonging to Haft Tappeh [5]. The unetched structure of samples under optical microscope and in SEM-BSE micrographs consist of some gray-green inclusions spread in the metallic matrix. SEM-EDS analysis of the inclusions shows they are consisting of $\mathrm{Cu}, \mathrm{S}$ and low amount of Fe, respectively (Figure 1). The composition of these inclusions represents copper sulfide compounds [7]. Also, some white inclusions are presented in SEM-BSE micrographs, which based on EDS analysis, they are lead globules that didn't resolved in copper matrix. A two phased microstructure is formed in one bronze sample that shows different tin content in two metallic phases. Totally, there are many differences in phases present in microstructure of seven samples. The etched microstructure of samples is not similar; in four samples, worked and recrystallized grains of $\alpha$ solid solution are presented that prove application of a cycle of cold-working and annealing to shape the metallic artefacts. In two samples, equi-axed and partially dendritic grains could be seen with some that represents some annealing to remove formed dendrites, however, the annealing process has not been enough to remove segregation. One sample has a considerable microstructure that is consisting of worked and twinned metal crystals with superimposed "ghost" dendritic structure upon recrystallized grains that shows coring occurred in original metal ingot [6].

Based on results, metal manufacturing in Haft Tappeh don't represents a similar procedure and shows application of different copper alloys (tin bronze, arsenic copper and copper) to make metallic artefacts. Manufacturing processes are cold working and annealing on copper ingots to shape different copper objects. Presence of copper sulfide inclusions proves smelting copper from sulfidic ores.

References:

[1] Thornton, C.P., Journal of World Prehistory 2 (2009), p.301-327. 
[2] Pigott, V.C., Persia's Ancient Splendour, Mining, Handicraft and Archaeology (2004), p. 28-43.

[3] Mofidi Nasrabadi, B., Persia's Ancient Splendour, Mining, Handicraft and Archaeology (2004), p. 294-308.

[4] Oudbashi, O. and Emami, S.M., Studies in Conservation 55 (2010), p.20-25.

[5] Oudbashi, O. et al, Proceedings of $36^{\text {th }}$ ISA Symposium (2009), p. 407-412.

[6] Scott, D. A. "Metallography and Microstructure of Ancient and Historic Metals" (Getty

Conservation Institute, Los Angeles).

[7] Klein, C. and Hurlbut Jr., C.S. "Manual of Mineralogy", (John Wiley and Sons, Toronto).

[8] The authors thank to B. Rahmani from RMRC to his helps for SEM-EDS analyses.

Table 1. SEM-EDS results of metallic matrix of 7 copper alloy fragments from Haft Tappeh (wt.\%)

\begin{tabular}{|c|c|c|c|c|c|c|c|c|c|}
\hline & $\mathrm{Cu}$ & Sn & $\mathbf{P b}$ & As & $\mathbf{S}$ & $\mathbf{N i}$ & $\mathbf{O}$ & $\mathbf{F e}$ & $\mathrm{Ca}$ \\
\hline HT.03-12/N & 97.79 & 0.22 & 0.40 & 1.59 & - & - & - & - & - \\
\hline HT.06-12/N & 97.01 & 2.61 & 0.21 & - & 0.17 & - & - & - & - \\
\hline HT.07-12/N & 95.07 & 4.16 & - & 0.05 & 0.71 & 0.01 & - & - & - \\
\hline HT.09-12/N & 95.82 & 4.18 & - & - & - & - & - & - & - \\
\hline HT.10-12/N & 96.96 & - & 0.29 & 2.75 & - & - & - & - & - \\
\hline HT.05-5-531/4 & 99.48 & 0.12 & - & - & - & - & 0.40 & - & - \\
\hline HT.10-95-72 & 89.75 & 7.06 & 2.24 & - & - & - & - & 0.58 & 0.35 \\
\hline
\end{tabular}

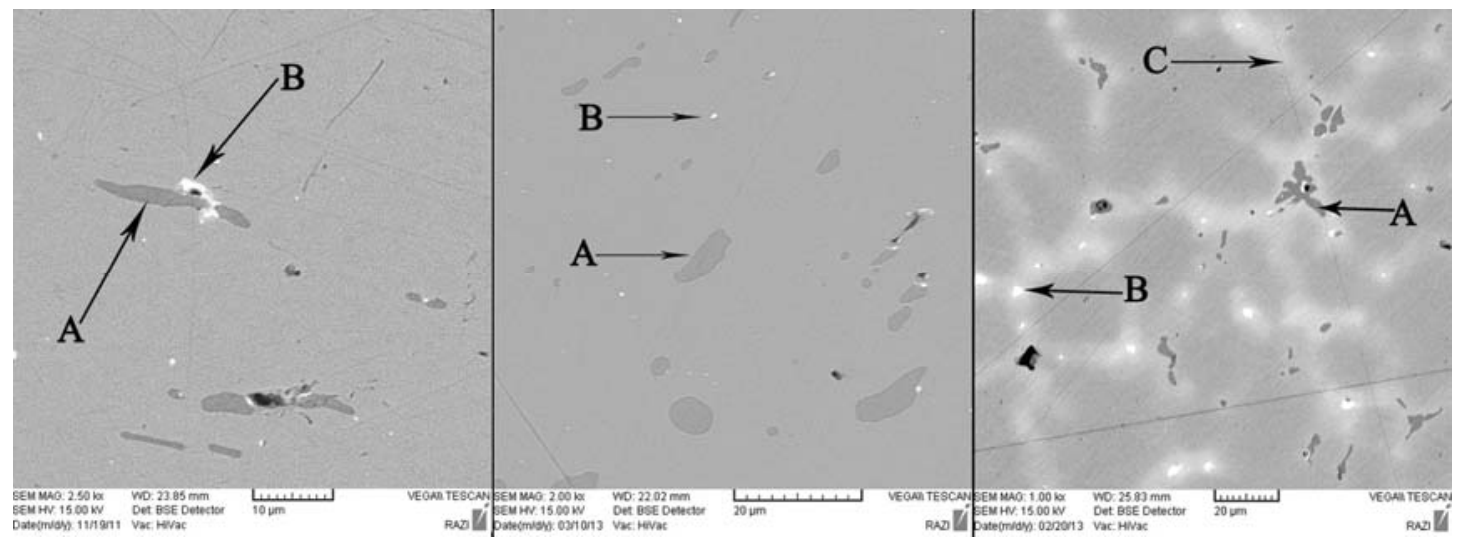

Figure 1. SEM-BSE micrograph of inclusions and Phases in Microstructure of three samples, Phase A is copper sulfides, $\mathrm{B}$ is lead globule and $\mathrm{C}$ is metallic phase with higher tin content.

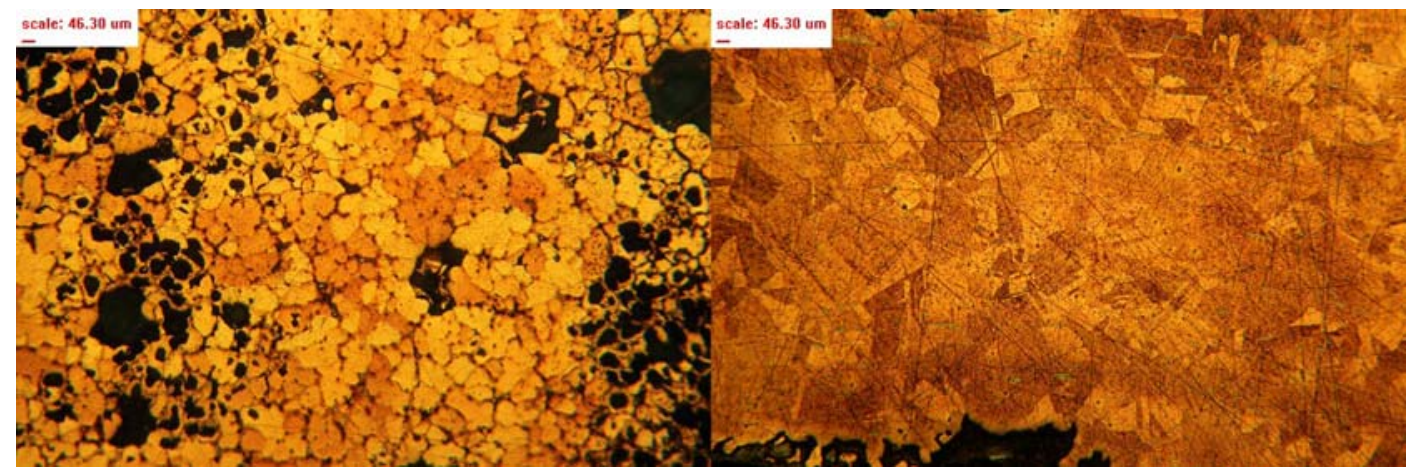

Figure 2. Etched microstructure of two samples, Left: annealed, equi-axed grains with remnants of dendritic structure, Right: Worked and twinned grains due to cycle of annealing and cold-working. 